\title{
A FENOMENOLOGIA COMO BASE EPISTEMOLÓGICA E ÉTICA DO MOVIMENTO DESALIENISTA NA FRANÇA E NO BRASIL 1
}

\author{
Phenomenology as an ethical and epistemological basis of the desalienist movement in France and in Brazil \\ La fenomenología como base epistemológica y ética del movimiento desalienista en Francia y en Brasil \\ TUDI GOZE \\ JULIANA PAIVA \\ LUCAS BLOC \\ JEAN NAUDIN \\ VIRGINIA MOREIRA
}

\begin{abstract}
Resumo: Este artigo tem como objetivo apresentar a fenomenologia como base epistemológica e ética do movimento desalienista da psicoterapia institucional na França e da Reforma Psiquiátrica no Brasil. Descrevemos estes dois movimentos e os principais nomes que fizeram parte de suas histórias em interlocução com a fenomenologia, refletindo sobre como esta pode ser considerada uma base para a prática de profissionais da saúde mental inseridos neste contexto que está em plena transformação. (Re)discutir tais bases nos parece de fundamental importância para reafirmar o sentido epistemológico e ético necessário que fundamenta ambos os processos. Concluímos que a fenomenologia se apresentou e ainda se apresenta como uma via de questionamento das práticas em saúde mental e oferece o fundamento para se pensar uma prática que busca o encontro com os sujeitos, e não somente com a doença mental, e para o processo de desinstitucionalização dos doentes mentais.
\end{abstract}

Palavras-chave: fenomenologia; movimento desalienista; reforma psiquiátrica.

\begin{abstract}
This article aims to present the phenomenology as the epistemological and ethical basis of the desalienist movement of institutional psychotherapy in France and the Psychiatric Reform in Brazil. We describe these two movements and the main names that were part of their stories in interlocution with phenomenology, reflecting on how this can be considered a basis for the practice of mental health professionals inserted in this context that is in full transformation. To discuss such bases seems to us to have a fundamental importance in order to reaffirm the necessary epistemological and ethical sense that underlies both processes. We conclude that phenomenology has been presented and still presents itself as a way of questioning mental health practices and offers the basis to think of a practice that seeks the encounter with the subjects and not only with the mental illness, as well as the process of deinstitutionalization of the mentally ill.
\end{abstract}

Keywords: phenomenology; desalienist movement; psychiatric reform.

Resumen: Este artículo tiene como objetivo presentar la fenomenología como base epistemológica y ética del movimiento desalienista de la psicoterapia institucional en Francia y de la Reforma Psiquiátrica en Brasil. Describimos estos dos movimientos y los principales nombres que formaron parte de sus historias en interlocución con la fenomenología, reflexionando sobre cómo ésta puede ser considerada una base para la práctica de profesionales de la salud mental insertados en este contexto que está en plena transformación. (Re)discutir tales bases nos parece de fundamental importancia para reafirmar el sentido epistemológico y ético necesario que fundamenta ambos procesos. Concluimos que la fenomenología se presentó y aún se presenta como una vía de cuestionamiento de las prácticas en salud mental y ofrece el fundamento para pensar una práctica que busca el encuentro con los sujetos y no sólo con la enfermedad mental y para el proceso de desinstitucionalización de los enfermos mentales.

Palabras-Clave: fenomenología; movimiento desalienista; reforma psiquiátrica

\section{Introdução}

O movimento desalienista, termo que devemos ao psiquiatra francês Lucien Bonnafé (1992), reúne um conjunto muito heterogêneo de movimentos intelectuais, clínicos e políticos visando a pôr em questão a instituição psiquiátrica a partir da segunda metade do século XX. Na França, este movimento assumiu um lugar significativo no pensamento psiquiátrico após a segunda guerra mundial. Já no Brasil, podemos destacar, a partir da década de 1930, o trabalho de Nise da Silveira que buscava transformar as práticas de cuidado em saúde mental utilizando a arte e o início efetivo do questionamento das práticas asilares que culmina com todo o processo da chamada Reforma Psiquiátrica.

Os movimentos da antipsiquiatria e da psicoterapia institucional podem ser destacados como parte da ampla discussão que envolveu o movi-

\footnotetext{
${ }^{1}$ Uma versão anterior deste trabalho foi o objeto de publicação em francês na revista Sud/Nord, 26 (1), Janeiro, 2016 e foi apresentada em português em versão reduzida em 2016, na ocasião do III Colóquio Internacional sobre a Clínica Humanista Fenomenológica e V Colóquio Nacional sobre a Clínica Humanista Fenomenológica em Fortaleza, Brasil. Os autores não tem nenhum conflito de interesse em relação a este artigo.
} 
mento desalienista na França. A antipsiquiatria é um movimento de pensamentos e de práticas que se construiu como uma oposição à psiquiatria dita "clássica". Proposto em 1967 pelo psiquiatra David Cooper em sua obra Psychiatrie et antipsychiatrie, o termo visa contemplar e agrupar um conjunto de ideias, de teorias e de práticas heterogêneas que visam combater os modelos vigentes da época em múltiplas dimensões (Puchivailo, Silva \& Holanda, 2013). Entre os principais representantes, além do próprio Cooper, podemos destacar o trabalho de Ronald Laing que trouxe contribuições importantes para o campo da saúde mental se utilizando de conceitos fenomenológicos e existenciais para a compreensão de fenômenos como a esquizofrenia e de Franco Basaglia, psiquiatra italiano, que criticava os modelos de classificação e a representação da loucura através do modelo das "doenças mentais" (Feys, 2017).

Já o chamado movimento da psicoterapia institucional nasceu da constatação de que a instituição psiquiátrica, se ela não se faz o objeto de uma reflexão crítica e clínica constante, pode ser responsável pelo agravamento das doenças mentais e, em especial, das psicoses graves. Esta constatação tomou uma dimensão trágica durante a segunda guerra mundial quando aproximadamente 40000 doentes mentais sucumbiram à fome nos hospitais psiquiátricos franceses entre 1940 e 1944 (Lafon, 2000). Este resultado se explica, em parte, pela indiferença e pelo esquecimento dos doentes mentais que eram objeto de raros protestos que buscavam defender seus direitos. Se, ao final da guerra, estas constatações iriam mobilizar a vanguarda psiquiátrica francesa, o movimento da psicoterapia institucional e da antipsiquiatria fizeram escolhas teóricas e políticas diferentes, principalmente no que diz respeito à natureza das doenças mentais.

No Brasil, as discussões acerca do tema do cuidado em saúde mental se aprofundaram a partir da segunda metade da década de 1970 com os questionamentos em relação à instituição asilar e à hegemonia da prática médica. A Reforma Psiquiátrica, ainda como movimento, começou a ser gestada, visando uma ampla reforma do modelo de assistência em saúde mental (Oliveira, 2009). Estes debates se deram, principalmente, por parte dos profissionais de saúde mental, em especial ao Movimento de Trabalhadores de Saúde Mental (MTSM), que denunciavam a falta de recursos e a negligência dentro dos hospitais psiquiátricos. A partir de então, a questão da humanização na assistência e a necessidade de diferentes tratamentos foi levantada e discutida no contexto brasileiro (Maciel, 2012).

Foi na década de 1980 que a desinstitucionalização começou a ser objeto de reflexão na área da saúde mental no Brasil. O Projeto de Lei do deputado federal Paulo Delgado, proposto em 1989, foi um marco neste processo de luta pelo direitos das pessoas com transtornos mentais ao propor a extinção progressiva dos hospitais psiquiátricos e sua substituição por dispositivos que ofereceriam terapêuticas alternativas aos doentes mentais, incluindo neste processo o próprio sujeito, a família e a comunidade. Trata-se de uma referência importante que indica a possibilidade de um processo reformador nos campos legislativos e normativo. Apesar de sua importância, este projeto sofreu resistência e passou por alterações significativas que culminaram com a aprovação de um substitutivo da Lei original: a Lei $\mathrm{n}^{\circ}$ 10.216. Aprovada em 2001, esta Lei significou um impulso para o processo de Reforma Psiquiátrica no Brasil e converge com a concepção de um movimento desalienista na medida em que volta atenção para a saúde mental preferencialmente comunitária em um processo de territorialização convergente com a lógica do Sistema Único de Saúde (SUS). Instituições como Hospitais Dia, Centros de Atenção Psicossocial (CAPS) e Lares Protegidos foram criados. Estes centros são compostos por equipes multiprofissionais e oferecem apoio ao doente mental, assim como à sua família (Maciel, 2012). É importante precisarmos que, mesmo antes da aprovação da Lei, havia no Brasil alguns chamados equipamentos substitutivos que merecem destaque por terem sido pioneiros nesta "nova" prática que visava substituir os manicómios; o Centro de Atenção Psicossocial (CAPS), em Itapeva (SP), e o Núcleo de Atenção Psicossocial (NAPS), em Santos (SP) são exemplos emblemáticos de um processo de mudança (Pereira \& Costa-Rosa, 2012).

Os movimentos que citamos nestes dois contextos significaram uma tentativa de romper com as práticas institucionais vigentes e resultam de questionamentos epistemológicos e éticos de seus principais autores. Dentre as bases que compuseram estas "lutas", destacamos a fenomenologia que, ao longo de sua história, contribuiu de modo significativo para a psicopatologia e para a compreensão da "doença mental" (Puchivailo, Silva \& Holanda, 2013; Schneider, 2009) e, para além de suas contribuições em nível teórico, permite um olhar diferenciado para os processos de adoecimento, para as práticas de cuidado e para uma reflexão política da ação (psico)terapêutica. Neste artigo, temos como objetivo apresentar a fenomenologia como base epistemológica e ética do movimento desalienista e da psicoterapia institucional na França e da Reforma Psiquiátrica no Brasil.

\section{A Base Fenomenológica da Psicoterapia Institucional na França}

Os psiquiatras que marcaram o movimento da psicoterapia institucional, em primeiro lugar François Tosquelles (1967) e Jean Oury (2007), conhecem perfeitamente a psiquiatria de língua alemã e seus empréstimos à filosofia de Husserl. A redução fenomenológica é utilizada por estes psiquiatras como um método filosófico, permitindo-lhes melhor fundamentar a experiência psiquiátrica sobre bases científicas rigorosas (Dorr, 2005). Não se trata de uma doutrina ou uma teo- 
ria dentre outras, mas de uma atitude pela qual o psiquiatra pode se distanciar dos clichês e teorias comumente admitidas para deixar aparecer no encontro o estilo de ser-no-mundo do paciente, respeitando a estrutura formal e abrindo-a progressivamente a um mundo por vezes compartilhável e responsável de seu poder-ser autônomo (Dorr, 2005). O que o senso comum tem por uma evidência natural, o método fenomenológico suspende momentaneamente. É assim que o método fenomenológico será, segundo Oury (2007), uma ferramenta preciosa para a desconstrução do estabelecimento psiquiátrico, da sua hierarquia, suas normas e seus preconceitos.

Permanecer nesta atitude é difícil, de fato impossível, deve-se sempre fazer o esforço de renová-la, colocar entre parênteses o que se acredita saber e olhar o que permanece, passar e repassar pelos ciclos do vivido, construir (abbau) e desconstruir (aufbau), numa "análise permanente da instituição" (Oury, 2007). Suspender o curso do que é estabelecido está associado ao movimento de institucionalização que porta o ser e o reúne na linguagem, na lei, no ritual, na cultura, ao seio do "grupo" e em nome do "coletivo", das " trocas" e da "rede". Na caixa de ferramentas da Psicoterapia Institucional, as noções de instituição e de estabelecimento se opõem pelas suas respectivas definições, como se opõe o instituinte ao instituído, o constituinte ao constituído pelo sujeito que efetua a épochè. Pode-se reconhecer o aporte sucessivo de Viktor Von Weizäcker (1958) e de Ludwig Binswanger no percurso que leva da redução eidética na qual parou Karl Jaspers à redução transcendental pela qual Binswanger, seguindo a Husserl, se dessolidariza de qualquer psicologia do Eu, após ao Dasein heideggeriano que rompe definitivamente com a noção cartesiana do sujeito pensado como um e indivisível (Heidegger, 1967). Ainda que a maioria dos profissionais que se dedicam hoje à Psicoterapia Institucional não se preocupe com a filosofia, ela permite esclarecer a relação de afinidade histórica da Psicologia Institucional com os pensamentos de Marx, Freud, Lacan e com as fenomenologias filosófica e clínica. Estes pensamentos fazem a divisão do sujeito individual, o "eterno vetor da verdade do ser". Se a corrente tradicional da psiquiatria fenomenológica é frequentemente distinta pela sua resistência tanto à psicanálise como ao materialismo dialético e se autores incontornáveis como Jaspers, Minkowski ou Schneider elaboraram concepções do mundo nas quais o estatuto epistemológico do inconsciente freudiano foi sistematicamente refutado (Jaspers, 1997), deve-se reconhecer à Psicoterapia Institucional uma pré-concepção filosófica da ação psicoterapêutica fundada sobre uma crítica radical da noção de sujeito inspirada pela fenomenologia.

A presença dos "fantasmas" filosóficos de Marx, Husserl e Heidegger na prática cotidiana da Psicoterapia Institucional francesa faz com que algo da revolução seja sempre esperado e nutre a força de resistência contra a ordem estabelecida dos que a praticam. Esta força de recusa se encontra em todos os lugares onde foi praticada a Psicoterapia Institucional, se opõe ao desumano do que é estabelecido e sedimentado para abrir espaços de acolhida e de troca que a institucionalização constrói como quadro terapêutico.

A elaboração do quadro de cuidados é correlativa desta função de acolhida. É um quadro ao qual nos inclinamos para receber a alteridade aos confins da loucura, a afirmação de um direito de abrigo. Este quadro intersubjetivo deve ser diferenciado radicalmente dos muros se, como o sublinha Roger Gentis (1975), os muros dos asilos não constituem unicamente limites de separação com o exterior, mas se prolongam invisivelmente ao interior, na intimidade protegida das pessoas que aí trabalham. Logo, a épochè é uma atitude radicalmente desalienista. Tosquelles (2009), justamente a este respeito distingue instituição e estabelecimento. O estabelecimento corresponde às regras editadas, prescritas e encarnadas na hierarquia. Aquilo que é instituído significa pôr em trabalho, minimamente, um espaço intersubjetivo. Uma instituição simbólica da linguagem que, longe de ser Lei, é, sobretudo, um debate permanente em co-construção no mundo comum da vida (Lebenswelt) (Moreira e Tatossian, 2016).

Esta discussão acerca do quadro de cuidados se mostrou de forma ambígua para a psicanálise, centrada sobre o modelo da transferência neurótica. Se, seguindo Freud, os psicanalistas consideraram que os esquizofrênicos são incapazes de transferência, Jean Oury terá a audácia de dialetizá-lo. Ele identifica uma transferência disassociada, despedaçada, multi-referenciada (Oury, 2012), em relação ao magma de investimentos postos em obra por certos pacientes sobre o conjunto de profissionais do cuidado. Mas, antes de poder pensar a transferência, trata-se de preparar o terreno, o tabuleiro do encontro, o quadro que permite o assentamento do colóquio singular, mas também condição de possibilidade do evento intersubjetivo. Um ambiente habitável, praticável, no qual o quadro é garantia de familiaridade e de evidência. Os "entornos" indispensáveis à experiência de uma realidade interior. Assim, mais ainda que a transferência, é o quadro como evidência mínima compartilhada que vai se refundar a cada vez. Como o sublinha Martine Girard, a psicose nos indica a "não-evidência à priori do quadro" (Girard, 2006). A perda da evidência natural (Blankenburg, 1991) torna necessário pôr em obra um pré-consciente auxiliar, uma fundação transcendental. Este quadro não é de regras, é de cuidados cotidianos, é um quadro que abre, que não preenche. Logo, pode sobrevir o encontro, o momento “ pático ” (Weiszäcker, 1958), momento que é, propriamente dizendo, um “ evento ” (Maldiney, 1976/1991).

A ideia de uma possível resistência do humano contra o desumano entra em profunda ressonância com as ideias de Von Weizsacker sobre o vivente e a norma, a qual, na relação osmótica que o homem entretem com seu meio (Umwelt) 
lhe permite superar singularmente as restrições contrárias à vida. Canguilhem (1943/2006, 1947), começa a trabalhar no hospital de Saint-Alban em Lozère durante a guerra, em 1943, que, na ocasião, era um refúgio para a resistência à ocupação nazista e ao regime fascita de Pétain. Lá, Canguilhem encontra François Tosquelles e Lucien Bonnafé e desenvolve estas ideias em seu ensaio sobre O normal e o patológico. Os muros de Saint-Alban acolhem todo tipo de homens livres, propícios a considerar que o humano, isto que é, propriamente dizendo, vivente em si, é capaz de modificar individualmente suas próprias normas para se adaptar ao seu meio, modificá-lo à medida que é preciso para continuar a viver. Paralelamente, ele anima a Sociedade do Gévaudan que pretende definir o trabalho de crítica radical e de invenção de instituições para alienados, feito pela equipe do Hospital de Saint-Alban. No início da década de 40, ele acolhe neste hospital Paul Éluard e multiplica os encontros pelo desenvolvimento da resistência intelectual. Estas ideias, longe de serem uma negação da doença e um repúdio à ciência, fazem valer que o viver e a doença tomam seu sentido conjunto na singularidade de cada um e os valores que cada homem retoma, a sua própria conta, ao constituir seu mundo. Em sua ligação fundadora com o meio, as instituições, como " criação dos homens ", são a forma cultural com o meio que emprestam a normatividade biológica e que faz o retorno a ela ao subdeterminá-la.

A doença obriga o doente a modificar seu mundo e a criar novas normas para sobreviver. Para Oury (2007), assim como para Tosquelles (2009), mesmo se a expressão de seus sintomas é culturalmente determinada e modificável ao articular técnicas de cuidados, atividades terapêuticas, participação ativa nas trocas, engajamento pessoal na tomada de fala e de responsabilidades ao seio do coletivo, a psicose é uma doença. A psicose é o motivo clínico incontornável, o "fato" sobre o qual o terapêutico engajado retorna sem cessar no movimento da psicoterapia institucional (Oury, 1993). Ela é, para o psiquiatra, isto que o fenomenológo chama de “a coisa mesma”. Não se trata somente de afirmar a existência da psicose, trata-se de "reconhecer" no encontro propriamente dito o fato psicótico e fazer da psicose, assim, a cada vez "algo de nosso próprio pathos": "Não existe Psicoterapia Institucional sem o reconhecimento do fato psicótico" (Roulot, 1973). O que a psicose é na intersubjetividade do encontro, a fenomenologia dá aos práticos as palavras mais justas para dizê-lo. O "sentimento do Praecox", isto que é, proprimente dito, sua "vivência" (tradução que propunha Tosquelles para a palavra Erlebnis), se encontra no que Minkowski (1927) descrevia como "perda do contato vital com a realidade", Binswanger como "falha transcendental" (Binswanger, 2006), e que Blankenburg (1991) chamará mais tarde, retomando as palavras de sua paciente Anne, a "perda da evidência natural". Os esquizofrênicos parecem restritos pela sua doença a viver uma forma específica de épo- ché, uma forma de afastamento da realidade da vida cotidiana que pode se manifestar nos seus retraimentos como na presunção delirante. O diagnóstico é atmosférico, é a presença do outro que se manifesta no encontro.

É porque a psicose tem para a Psicoterapia Institucional, como para a fenomenologia, a estrutura epistemológica do "evento" (Maldiney, 2007), quer dizer: o enfoque não está na constituição de uma estrutura de personalidade "psicótica", mas no encontro intersubjetivo, visto que a psicoterapia institucional considera que o ponto nodal da existência da psicose é esta relação intersubjetiva, ressaltando, assim, o acolhimento ao paciente. A psicose somente encontra sua realidade concreta no evento do encontro. Deve-se, portanto, posicionar as condições de possibilidade de sua aparição, de seu acolhimento. Avaliar e cuidar supondo preservar seu estilo, sua opacidade, sem danificar mais ainda o narcisismo originário no qual a presença pode ainda esperar se fundar, se fundir ou se retirar. Aprender, ao trabalhar a humanidade da acolhida ao deixar ser e se implantar a presença sem ignorar, no entanto, o poder próprio da psicose em desfazer as ligações e desconstruir o sentido comum. Cuidar sem se demorar nos sintomas. Não tê-los como alvo. Mas, não fingir que eles não existem. Aprender a modificar o ambiente em direção a mais humanidade. Aprender a trabalhar tomando como quadro a cotidianidade da vida, seu ritmo, as mudanças que a estruturam e formam a carne, por assim dizer "o tecido conjuntivo" (Merleau-Ponty, 1964) que institui o caráter radical de nossa coexistência.

O trabalho clínico consiste em organizar o que Oury (2012) chama de "pontos de encontro", que não podem se reduzir à existência de um espaço dedicado ao quadro administrativo, por exemplo, de um hospital-dia. A fenomenologia, no sentido de um método, só tem sentido se praticada no mundo-da-vida (Lebenswelt) como um questionamento permanente, filosófico e político, das instituições e das práticas que fazem parte do quadro. Porque eles são feitos por homens e com homens, os diversos dispositivos terapêuticos não devem ser fixados, mas concebidos como seres vivos. A evolução dos dispositivos no tempo responde às diversas situações atravessadas pelos homens, nos períodos da história, nos momentos de inércia ou estabilidade, à economia, às situações de crise. A psicose permanece como um invariante que não cessa de refletir a agitação como o tédio dos homens, sua capacidade de revolta como de recuo. A alienação social e a alienação psicopatológica (Oury, 1993) se refletem uma na outra como em um espelho e ressonam amplamente nos momentos de crise.

É sobre este último ponto da dupla significação da alienação que são claramente diferenciadas, e frequentemente opostas frontalmente, os apoiadores da Psicoterapia Institucional e estes da antipsiquiatria ou do movimento Psichiatria democratica na Itália. Se nos mantivermos na contribuição específica do método fenomenoló- 
gico em seu nascimento, todos deveriam tê-los aproximado. Pela importância dada à redução e ao mundo da vida (Lebenswelt) que eles fazem aparecer ao desconstruí-lo, a antipsiquiatria e a psicoterapia institucional são primas próximas, para não dizer irmãs de leite. As noções de experiência vivida, de intersubjetividade constituinte, de projeto e de situação formam na fenomenologia existencial como que germes de revolta para quem quer extrair daí a significação política. Identifica-se nos textos de autores muito diferentes como Frantz Fanon (1961/2002), Franco Basaglia (Basaglia, 1981), Michel Foucault (1964) ou Félix Guattari (2012) como que um "ar de família”. Todos passaram pela fenomenologia e veem na alienação clínica uma ilusão construída pelo poder dominante. Sartre vai inspirar a revolta crítica de Franz Fanon e, alguns anos mais tarde, a visão existencial de Ronald Laing (1976). Basaglia, tradutor de Husserl, encontra na redução fenomenológica o poder de suspender qualquer abordagem diagnóstica para retornar à única humanidade da pessoa doente e abater os muros do asilo.

Foucault, antes de escrever sua História da loucura à idade clássica traduz Binswanger e Von Weizsäcker. Sua concepção genealógica da História e da doença, critivável tanto sobre o plano crítico quanto sobre o plano histórico, é, antes de tudo, husserliana. O ponto sensível do conflito entre Psicoterapia Institucional e Antipsiquiatria será o estatuto clínico da psicose. "Reduzamos, mas não trapaceemos”, dizia Tosquelles. Face ao desastre que constitui a psicose sobre o ser-no-mundo, a ética clínica da Psicoterapia Institucional lhe terá permitido esperar tratá-la sem jamais negá-la. Mas as instituições e os grupos que elas ordenam nascem e se projetam como homens no espaço e no tempo. Elas se transmitem, vivem e morrem no ritmo das gerações. Como o apontava Tatossian (1984/2014), as instituições têm, no fundo, numerosos pontos em comum com a família. Instituidoras de normas compartilhadas, elas não são sempre felizes e sabem recriar à sua própria maneira, na dupla ligação, o fechamento contra o qual elas pretendem lutar.

\section{As Contribuições da Fenomenologia para a Reforma Psiquiátrica no Brasil}

A discussão da reforma psiquiátrica no Brasil se restringe, muitas vezes, às implicações práticas e aos efeitos jurídicos de sua efetivação, principalmente a partir de 2001 com a aprovação da Lei 10.216. Uma discussão epistemológica e teórica de suas bases merece atenção. Ao se tratar de uma reforma estrutural do modelo de atenção (Oliveira, 2009), os argumentos que justificavam a necessidade de mudança devem ser claros e assentados em uma plataforma ética. Neste sentido, a fenomenologia, ao adentrar no campo da saúde mental, se apresenta como uma epistemologia de caráter crítico, como uma filosofia que permite uma efetiva reflexão da realidade e como uma metodologia de acesso a esta realidade (Holanda, 2009) que vem sendo utilizada como uma das bases do movimento contemporâneo de saúde mental (Oliveira, 2009). A participação da fenomenologia faz parte de um processo histórico que envolveu a lógica da saúde mental a partir do início do século XX e que permitiu que ela se apresentasse, segundo Schneider (2009), como "a principal perspectiva filosófica que sustenta a ruptura com a lógica determinista predominante" (p. 70). Assim, para além das modificações físicas dos equipamentos, a Reforma Psiquiátrica brasileira é "resultado de complexas discussões da compreensão sobre o conceito (de Saúde Mental) e os múltiplos sentidos com respeito à 'loucura'” (Puchivailo, Silva \& Holanda, 2013, p. 233); reflexões em parte oriundas direta e indiretamente da fenomenologia.

Ao buscarmos as bases e as influências da Reforma Psiquiátrica brasileira, podemos destacar, inicialmente, o modelo de desinstitucionalização italiano com principal referência dos trabalhos de Franco Basaglia e as contribuições de Ronald Laing e David Coopper. Estes autores, importantes no processo brasileiro ao fornecerem novos paradigmas teóricos e modelos práticos, foram influenciados pela compreensão fenomenológica e pelos psiquiatras fenomenólogos, tais como Jaspers e Minkowski, que propõem outra via clínica do cuidado em saúde mental. $\mathrm{Na}$ proposta de Laing, por exemplo, é retomada a perspectiva que Jaspers defendia em 1913 no livro Psicopatologia Geral de uma base fenomenológico-existencial para a compreensão dos fenômenos psíquicos e para a proposição do cuidado em saúde. O paciente passaria, então, a ser visto "como pessoa, a doença passa a ser vista como estado, e o terapeuta personagem distante e superior, assumindo uma postura de igualdade para com o paciente, no que concerne a direitos e status de cidadão" (Oliveira, 2009, p. 58).

As reflexões de Basaglia, Laing e Cooper, de cunho fenomenológico e existencial, chegaram ao Brasil e afetaram o movimento da reforma na saúde mental (Puchivailo, Silva \& Holanda, 2013). Trata-se de uma "abertura" que indica uma mudança de paradigma que passa a enfatizar aspectos como a reabilitação psicossocial, a reintegração do sujeito em seu próprio contexto, o resgate da subjetividade a partir e o trabalho em "rede" que marca, por exemplo, o trabalho nos Centros de Atenção Psicossocial (CAPS). Como concluem Puchivailo, Silva e Holanda (2013), estas medidas adotadas convergem com as ideias difundidas por uma série de pensadores da filosofia e da psiquiatria fenomenológicas. Ainda que de forma indireta, ou seja, a partir da influência sofrida pelos psiquiatras assinalados, podemos reconhecer a marca de uma compreensão fenomenológica e existencial no sentido dado ao movimento da reforma brasileira.

De forma mais direta, podemos destacar no Brasil a influência da ideia de desinstitucionali- 
zação envolvendo a sociedade proposta por Basaglia. Amarante (2010) aponta que a originalidade de Basaglia está em sua forma de pensar as questões da loucura e a forma de tratá-la que está embasada nas ideias de diversos autores, entre eles destacam-se vários da tradição fenomenológica: Husserl, como dito acima; mas também Sartre, Heidegger, Merleau-Ponty e Binswanger. A partir da leitura de Sartre, Basaglia começa a pensar a instituição psiquiátrica como uma escolha deliberada, que não é pessoal, mas global; como um modo de ser-no-mundo, quer dizer, a instituição funciona de forma a excluir o que é diferente a fim de afirmar sua força e esta forma de funcionamento é considerada uma escolha. Desta forma, pode-se pensar outros modos de funcionamento da instituição psiquiátrica, pensando a prática como realidade renovável (Amarante, 2010). Através da fenomenologia, produz-se um questionamento e volta-se para o sujeito como centro da questão tanto em psicopatologia quanto na atenção à saúde mental. Assim, sob a influência de Basaglia, passa-se a conceber as formas de tratamento como "consequências do olhar que se tem à doença mental" (Puchivailo, Silva e Holanda, 2013, p. 237). Há, no contexto brasileiro, um processo de ruptura no campo setorial da saúde que advém da própria práxis e de um processo de reflexão que é perpassado pela tradição fenomenológica.

Se, por um lado, a Reforma Psiquiátrica brasileira se apresentou sob influência da fenomenologia existencial e da Psiquiatria Democrática italiana a partir, principalmente, da figura de Franco Basaglia, por outro, uma série de dilemas bioéticos (Oliveira, 2009) foram aparecendo e que dizem respeito, sobretudo, à dificuldade do processo de (des)institucionalização que está na base do processo reformatório. Este é um ponto crucial na medida em que se pode afirmar que a "a ética da RP funda-se na abordagem fenomenológica-existencial e apoia-se no conceito de desinstitucionalização" (Oliveira, 2009, p. 60). A proposta significa o advento de uma práxis que coloca as instituições como parte de uma rede de cuidados que se volta para a cidadania plena dos usuários dos serviços. Trata-se de um processo de desinstitucionalização que visa gerar novos atores sociais, produzir espaços para se pensar e se intervir na saúde das pessoas, resgatando a complexidade da vida psíquica - um modelo que rompe com a centralidade do paradigma médico e visa permitir a expressão de novas formas de subjetivação (Oliveira, 2009). Como todo processo de reforma, existiram e existem resistências.

É importante ressaltar que, no contexto brasileiro, o novo modelo de assistência aos doentes mentais propostos, por exemplo, nos Centros de Atenção Psicossocial (CAPS) e nos Hospitais Dia tem buscado acolher, (re)inserir este sujeito na sociedade, envolvendo a comunidade e a família no tratamento. A "loucura" passou a ser debatida entre os profissionais da área de saúde mental com o objetivo de desenvolver um quadro terapêuti- co que melhor proporcione um encontro não só com a doença mental, mas com o próprio sujeito. Assim pode-se dizer que no Brasil, foram criados diversos novos serviços a fim de suprir a demanda de pacientes saídos dos hospitais psiquiátricos. Entretanto, o que se tem observado é que o objetivo proposto de reabilitação dos pacientes psiquiátricos e sua reinserção na sociedade não vem sendo cumprido de forma satisfatória, como afirma Amarante (2010): “(...) em uma palavra, aumentam o número de pessoas assistidas e as possibilidades de intervenção técnica, sem que os resultados terapêuticos sejam correspondentes." (p. 17).

\section{Considerações Finais}

Face à cronicidade mais forte que os movimentos que a combatem, face à inércia tão prontamente instalada nas estruturas hospitalares como nas cabeças dos homens, face à força mortífera da repetição, diversas formas novas, diversos movimentos têm, nas últimas décadas, visado a desalienação: desinstitucionalização, antipsiquiatria, psiquiatria comunitária, recovery approach e a Reforma Psiquiátrica no Brasil.

O contexto psiquiátrico foi regularmente abalado por profissionais nos quais a fenomenologia se fazia aliada a um engajamento político em torno dos doentes mentais como da sociedade civil afim de não mais considerar como estabelecido uma vez por todas a dominação qualquer de um grupo sobre um outro. É desta relação eletiva entre a filosofia fenomenológica e a ação psicoterapêutica que nós ensaiamos abordar neste artigo. Sobre este assunto, nós faríamos de bom grado nossa a fala de Henri Maldiney : "Se a atitude fenomenológica em psiquiatria tivesse prevalecido, a antipsiquiatria não teria nascido" (Maldiney, 1976/1991). Para além de um conceito filosófico, trata-se de uma atitude que afeta o contato com o paciente, os modos de cuidado e potencializa a expressão de um sujeito em sofrimento que, muitas vezes, se depara com uma assistência que restringe suas possibilidades ao significar muito mais uma barreira com a sociedade do que uma via de (re)construir uma dinâmica da relação do sujeito com o mundo. Assim, a partir, por exemplo, do conceito de époché husserliano, psiquiatras como Franco Basaglia, por exemplo, começaram a construir novas ideias de prática com os doentes mentais que não focassem no enquadre em sintomas psiquiátricos, mas que os pusessem entre parênteses a fim de se pensar o sujeito doente no mundo em que está inserido, considerando o seu entorno como constituidor do seu modo de estar-no-mundo.

A fenomenologia serviu como base para se pensar a psicoterapia institucional e a Reforma Psiquiátrica no Brasil no sentido de fundamentar um olhar para a doença mental diferente daquele da psiquiatria tradicional e de assegurar uma ética do sujeito que visa recompor a dinâmica 
de suas relações e romper as amarras das instituições. No caso da psicoterapia institucional na França, consideramos que a base epistemológica e ética oriunda da fenomenologia é mais clara e, poderíamos assim dizer, mais explorada na medida em que houve uma maior aproximação teórica dos principais agentes. No caso do Brasil, ainda que apontemos tais influências, ela se deu de forma mais indireta e foi sobreposta por discussões político-econômicas e estruturais que minimizam tais fontes. (Re)discutir tais bases nos parece de fundamental importância para reafirmar o sentido epistemológico e ético necessário que fundamenta ambos os processos. A fenomenologia se apresentou e ainda se apresenta, certamente, como uma via de questionamento das práticas em saúde mental e, como bem ela se afirma desde seu nascimento, um retorno é sempre necessário.

\section{Referências}

Amarante, P. (2010). O homem e a serpente: outras histórias para a loucura e a psiquiatria. Rio de Janeiro: Editora Fiocruz

Basaglia, F. (1981). Scritti. Dalla psichiatria fenomemnologica all'esperienza du Gorizia (Vol. 1). Torino : Einaudi.

Binswanger, L. (2006). Trois formes manquées de la présence humaine. Paris : Le Cercle Herméneutique.

Blankenburg, W. (1991). La perte de l'évidence naturelle : une contribution à la psychopathologie des schizophrénies pauci-symptomatiques. Paris : Presses universitaires de France.

Bonnafé, L. (1992). Désaliéner ? Folie(s) et société(s). Mirail, Toulouse : Presses universitaires.

Canguilhem, G. (1943/2006). Le normal et le pathologique. Paris : PUF, Quadrige.

Canguilhem, G. (1947). La situation faite en France à la philosophie biologique. Revue de métaphysique et de morale.

Dorr, O . (2005). La fenomenología psiquiátrica como epistemología y sus consecuencias terapéuticas. Revista de neuro-psiquiatría, 68(1-2), 2-15.

Fanon, F. (1961/2002). Les damnés de la terre. Paris : La découverte.

Feys, J-F. (2017). Les fondements constructivistes de l'antipsychiatrie. L'information psychiatrique, 93(6), 457-463.

Foucault, M. (1964). Histoire de la folie à l'âge classique. Paris : Gallimard.

Gentis, R. (1975). Les murs de l'asile. Paris : Maspero

Girard, M (2006). L'accueil en pratique institutionnelle. Edition du Champ Social, Paris.
Guattari, F. (2012). De Leros à la Borde. Paris: Nouvelles Éditions Ligne.

Holanda, A. (2009). Fenomenologia e Psicologia: diálogos e interlocuções. Revista da Abordagem Gestáltica, 15(2), 87-92.

Heidegger M. (1967). Sein und Zeit. Verlag : Tübingen.

Jaspers, K. (1997). General Psychopathology vol. I. Baltimore : The Johns Hopkins University Press.

Lafont, M. (2000). L'Extermination douce. La Cause des fous 40000 malades mentaux morts de faim dans les hôpitaux sous Vichy. Matresne : Le Bord de l'eau édition.

Laing, R. (1976). La politique de l'expérience. Essai sur l'aliénation et l'oiseau de paradis. Paris : Paperback.

Maciel, S.C. (2012). Reforma psiquiátrica no Brasil : algumas reflexões. Caderno Brasileiro de Saúde Mental, 4(8), 73-82.

Maldiney, H. (1976). Psychose et présence. In : Maldiney, $\mathrm{H}$ (1991). Penser l'homme et la folie. A la lumière de l'analyse existentielle et de l'analyse du destin. Grenoble : Million, pp. 5-82.

Maldiney, H. (2007). "Évènement et psychose.”. In : Maldiney (1991). Penser l'homme et la folie. Paris : Édition Jérôme Million.

Merleau-Ponty, M. (1964). Le visible et l'invisible. Paris : Éditions Gallimard.

Minkowski, E. (1927). La schizophrénie. Paris : Éditions Payot.

Oliveira, W. F. (2009). Éticas em conflito: reforma psiquiátrica e lógica manicomial. Cadernos Brasileiros de Saúde Mental, 1(2), 48-61.

Oury, J. (1993). L'aliénation. Paris : Galilée.

Oury, J. (2003). Transfert, multiréférentialité et vie quotidienne dans l'approche thérapeutique de la psychose. Cahiers de psychologie clinique, $\mathrm{n}^{\circ} 21,155-165$.

Oury, J. (2007). Psychanalyse, psychiatrie et psychothérapie institutionnelles. Vie sociale et traitements, $\mathrm{n}^{\circ}$ 95, 110-125.

Oury, J. (2012). Préalables à toute clinique des psychoses : dialogue avec Patrick Faugeras. Toulouse : Érès.

Pereira E. C. \& Costa-Rosa, A. (2012). Problematizando a Reforma Psiquiátrica na Atualidade: a saúde mental como campo da práxis. Saúde e Sociedade, 21(4), 1035-1043.

Puchivailo, M. C., Silva, G. B. \& Holanda, A. F. (2013). A reforma na saúde mental no Brasil e suas vinculações com o pensamento fenomenológico. Revista da Abordagem Gestáltica, 19(2), 230-239.

Roulot, D. (1973). Phénoménologie et psychothérapie institutionnelle. Thèse pour le doctorat en médecine, Paris. 
Schneider, D. R. (2009). Caminhos históricos e epistemológicos da psicopatologia: contribuições da fenomenologia e existencialismo. Cadernos Brasileiros de Saúde Mental, 1(2), 62-76.

Tatossian, A. (1984). Famille et institution : le sujet comme enjeu. In: Tatossian, A. (1997/2014). Psychiatrie phénoménologique, MJW Fédition, Paris, 2014.

Tatossian, A. \& Moreira, V. (2016). Clinique du Lebenswelt: psychothérapie et psychopathologie phénoménologiques. Paris : MJW Fédition.

Tosquelles, F. (1967/2009). Le travail thérapeutique en psychiatrie. Toulouse : Érès.

Tosquelles, F. (2009). Le travail thérapeutique en psychiatrie. Toulouse, Érès.

Weiszäcker, V. (1958). Le cycle de la Structure. Paris : Desclée de Brouwer.

Tudi Gozé, Service de Psychiatrie, Psychothérapies et Art-thérapie, CHU de Toulouse (France). Equipe de Recherche sur les Rationalités Philosophiques et les Savoirs (ERRaPhiS - EA 3051), Université de Toulouse.

Juliana Ribeiro de Paiva, Universidade de Fortaleza - Laboratório de Psicopatologia e Clínica Humanista Fenomenológica (APHETO). Email: juliana.ribeiro. paiva@hotmail.com

Lucas Bloc, Universidade de Fortaleza - Laboratório de Psicopatologia e Clínica Humanista Fenomenológica (APHETO).

Jean Naudin, CHU Sainte-Marguerite, AP-HM, Université Aix-Marseille (France)

Virginia Moreira, Universidade de Fortaleza Laboratório de Psicopatologia e Clínica Humanista Fenomenológica (APHETO).

Recebido em 20.07.2017

Primeira Decisão Editorial em 21.12.2017

Aceito em 05.05.2018 